\title{
An Effective Alternative New Approach in Solving Transportation Problems
}

\author{
Ekanayake E. M. U. S. B. ${ }^{1,}$, , Perera S. P. C. ${ }^{2}$, Daundasekara W. B. ${ }^{3}$, Juman Z. A. M. S. ${ }^{3}$ \\ ${ }^{1}$ Department of Physical Sciences, Faculty of Applied Sciences, Rajarata University of Sri Lanka, Mihinthale, Sri Lanka \\ ${ }^{2}$ Department of Engineering Mathematics, Faculty of Engineering, University of Peradeniya, Peradeniya, Sri Lanka \\ ${ }^{3}$ Department of Mathematics, Faculty of Science, University of Peradeniya, Peradeniya, Sri Lanka
}

\section{Email address:}

uthpalaekana@yahoo.com (Ekanayake E. M. U. S. B.), pperera@pdn.ac.lk (Perera S. P. C.), wbd@pdn.ac.lk (Daundasekara W. B.), jumanabdeen@yahoo.com (Juman Z.A. M. S.)

${ }^{*}$ Corresponding author

\section{To cite this article:}

Ekanayake E. M. U. S. B., Perera S. P. C., Daundasekara W. B., Juman Z. A. M. S. An Effective Alternative New Approach in Solving Transportation Problems. American Journal of Electrical and Computer Engineering. Special Issue: Artificial Intelligence in Electrical Power \& Energy. Vol. 5, No. 1, 2021, pp. 1-8. doi: 10.11648/j.ajece.20210501.11

Received: July 15, 2020; Accepted: January 23, 2021; Published: January 30, 2021

\begin{abstract}
The Transportation problem is one of the most colorful and demanding problems in the history of Operations Research. Many researchers have paid attention to solve the problem using different approaches. In certain approaches focused on finding an initial basic feasible solution and the other to find the optimal solution. It can be noticed that these methods have advantages and disadvantages. Out of all the methods that can be found in the literature, Northwest, Least Cost and Vogel's Approximation methods are the most prominent and renowned methods in finding an initial basic feasible solution. Also, the Modified Distribution (MODI) Method and Stepping Stone Method are the most acceptable methods in finding the optimal solution to the transportation problem. In this research paper, we propose an alternative method that finds the optimal or nearly optimal solution to the transportation problem. This method which is based on an iterative algorithm can be applied to balance as well as unbalanced transportation problems. It is also to be noticed that this method requires a minimum number of iterations to reach the optimality as compared to the other existing methods. Also, we have developed a new method of finding an optimal solution for both balanced and unbalanced transportation problems.
\end{abstract}

Keywords: Transportation Problem, Optimal Solution, Balance, Unbalance and Optimal Solution

\section{Introduction}

The transportation problem is likewise one of the extraordinary kinds of Linear Programming problems in which the objective is to transport various quantities (goods) initially stored at different origins/plants/factories to various destinations/distribution centers/warehouses in such a way that the total transportation cost is minimized. To accomplish this objective, we should decide the number of available supplies and the quantities demanded. Also, we should decide the transportation costs from various origins to various destinations.

The transportation problem (TP) was first formulated by Hitchcock [11] and was independently treated by Koopmans and Kantorovich. Monge [21] defined it and unraveled it by mathematical methods. Hitchcock [11] developed the major transportation problem; anyway just in 1951, after the introduction of the Simplex Algorithm by George B. Dantzig [6], complex transportation problems which stirred in business were solved and found optimal solutions. Be that as it may, a few analysts concentrated broadly in finding alternative methods to solve cost-minimizing transportation problems considering its exceptional structure.

In the literature, a few heuristic solutions approach such as the Northwest corner method (NWCM) by charnes and Cooper, minimum cost method [5], VAM - Vogel's approximation method [22], JHM - Juman and Hoque's method [15], GVAM - Goyal's version of VAM [9], EHA- An Efficient Heuristic Approach [14], etc. were proposed to obtain an Initial Feasible Solution (IFS) to the TP. Also, Stephen Akpana et al. [2] developed A Modified Vogel Approximation Method for Solving Balanced Transportation Problems. Wali Ullah et al. [24], A Modified 
Vogel's Approximation Method for Obtaining a Good Primal Solution of Transportation Problems. Eghbal Hosseini [12], Three New Methods [Total Differences Method 1 (TDM1, TDM2) and Total Differences lest Squares Method 1 (TDSM)] to Find Initial Basic Feasible Solution of Transportation Problems. Mollah Mesbahuddin Ahmed at al. [3], presented A New Approach to Solve Transportation Problems. Juman and Nawarathne [16] presented an alternative approach to solving a TP.

This paper proposes an algorithm to solve the TP which gives a quicker union rate contrasted with existing methods in the literature.

\section{Mathematical Formulation}

Let us assume that in general that a particular product is manufactured in $m$ production plants known as sources denoted by $S_{1}, S_{2}, \ldots, S_{m}$ with respective capacities $a_{1}, a_{2}, \ldots, a_{m}$, and total distributed to $n$ distribution centers known as sinks denoted by $D_{1}, D_{2}, \ldots, D_{m}$ with respective demands $b_{1}, b_{2}, \ldots, b_{n}$. Also, assume that the transportation cost from $\mathrm{i}^{\text {th }}$ - source to the $\mathrm{j}^{\text {th }}$ - $\operatorname{sink}$ is $C_{i j}$ and the amount shipped is $X_{i j}$, where $i=1,2, \ldots, m$ and $j=1,2, \ldots, n$.

Mathematical Model:

The total transportation cost is

Minimize $\sum_{i=1}^{m} \sum_{j=1}^{n} X_{i j} C_{i j}$

Subject to the constraints

i. $\quad \sum_{j=1}^{n} X_{i j}=a_{i}, i=1,2, \ldots, m$

ii. $\sum_{i=1}^{m} X_{i j}=b_{j}, j=1,2, \ldots, n$ (3.3) and

iii. $X_{i j} \geq 0$ for all $i=1,2, \ldots, m$ and $j=1,2, \ldots, n$

Note that here the sum of the supplies equals the sum of the demands. i.e. $\sum_{i=1}^{m} a_{i}=\sum_{j=1}^{n} b_{j}$. Such problems are called balanced transportation problems and otherwise, i.e. $\sum_{i=1}^{m} a_{i} \neq \sum_{j=1}^{n} b_{j}$, known as unbalanced transportation problems.

i. $\sum_{i=1}^{m} a_{i}>\sum_{j=1}^{n} b_{j}$

ii. $\sum_{i=1}^{m} a_{i}<\sum_{j=1}^{n} b_{j}$

Introduce a dummy origin in the transportation table; the cost associated with this origin is set equal to zero. The availability at this origin is: $\sum_{i=1}^{m} a_{i}-\sum_{j=1}^{n} b_{j}=0$.

\section{Proposed Algorithm to Solve the TP}

The proposed method can be applied to solve balanced and unbalanced TPs.

Step 1: Formulate the Transportation Cost Matrix. If the problem is unbalanced, make it a balanced problem by introducing a dummy source or a dummy destination accordingly.
Step 2: Identify the cell for allocation which has the least unit transportation cost $\left(c_{i j}\right)$ in each row and columns.

Step 3: If the least cost of any row is the least cost of any column, then select those least costs.

Step 4: Crossed off the rows and columns of the least costs obtained in Step 3.

Step 5: Repeat steps 2 to 4 for uncrossed rows and columns until at least one cell is marked in each row and each column

Step 6: First allocate min (ai, bj) amount of units without violating the demand and supply to the cell of the least cost in the priority with the above step and update the supply and demand

Step 7: Repeat Step 6 for the next least cost and continue until all the selected cells run out.

Step 8: Extract the initial feasible solution

\section{Solution of a Problem with Illustration}

Consider the following transportation problem:

\begin{tabular}{llllll}
\hline Destination/Sources & $\boldsymbol{D}_{\mathbf{1}}$ & $\boldsymbol{D}_{\mathbf{2}}$ & $\boldsymbol{D}_{\mathbf{3}}$ & $\boldsymbol{D}_{\mathbf{4}}$ & Su. \\
\hline$S_{1}$ & 10 & 8 & 4 & 3 & 500 \\
$S_{2}$ & 12 & 14 & 20 & 2 & 400 \\
$S_{3}$ & 6 & 9 & 23 & 25 & 300 \\
Dem. & 250 & 350 & 600 & 150 & \\
\hline
\end{tabular}

Following the Step 2, Step 3, Step 4 and Step 5:

\begin{tabular}{llllll}
\hline Destination/Sources & $\boldsymbol{D}_{\mathbf{1}}$ & $\boldsymbol{D}_{\mathbf{2}}$ & $\boldsymbol{D}_{\mathbf{3}}$ & $\boldsymbol{D}_{\mathbf{4}}$ & Su. \\
\hline$S_{1}$ & 10 & 8 & $4^{*}$ & 3 & 500 \\
$S_{2}$ & 12 & 14 & 20 & $2 *$ & 400 \\
$S_{3}$ & $6^{*}$ & 9 & 23 & 25 & 300 \\
Dummy Row & 0 & 0 & 0 & 0 & 150 \\
Dem. & 250 & 350 & 600 & 150 & \\
\hline
\end{tabular}

Following the Step 6 and Step 7:

\begin{tabular}{lllll}
\hline 10 & 8 & $4 * 500$ & 3 & 5000 \\
12 & $14 * 250$ & 20 & $2 * 150$ & $400 * 250 * 0$ \\
$6 * 250$ & $9 * 50$ & 23 & 25 & $300 * 50 * 0$ \\
0 & $0 * 50$ & $0 * 100$ & 0 & $150 * 100 * 0$ \\
$250 * 0$ & $350 * 300 * 50 * 0$ & $600 * 100 * 0$ & $150 * 0$ & \\
\hline
\end{tabular}

According to Step 8:

Total cost $=4 \times 500+14 \times 250+2 \times 150+6 \times 250+9 \times 50=7,750$

\section{A Comparison of the Methods}

The comparisons of the results are studied in this research to measure the effectiveness of the proposed method. The detailed representation of the numerical data of Table 1 . is provided in Appendix 1. [4].

Table 1. Comparative results of NWCM, LCM, VAM, IAM and New Approach (NEWA) for 10 benchmark instances.

\begin{tabular}{|c|c|c|c|c|c|c|c|c|c|c|c|}
\hline \multirow{2}{*}{ Ahamd et al...(2016) } & \multicolumn{6}{|l|}{ TCIFS } & \multirow{2}{*}{$\begin{array}{l}\% \text { increase } \\
\text { NWCM }\end{array}$} & \multirow{2}{*}{$\begin{array}{l}\text { from } \\
\text { LCM } \\
\end{array}$} & \multirow{2}{*}{$\begin{array}{l}\text { the } \\
\text { VAM } \\
\end{array}$} & \multirow{2}{*}{$\begin{array}{l}\text { minimal } \\
\text { IAM }\end{array}$} & \multirow{2}{*}{$\begin{array}{l}\text { total cost } \\
\text { NEWA }\end{array}$} \\
\hline & NWCM & LCM & VAM & IAM & NEWA & OPTIMAL & & & & & \\
\hline BTP-1 & 1,500 & 1,450 & 1,500 & 1,390 & 1,390 & 1,390 & 7.91 & 4.31 & 7.91 & 0.00 & 0.00 \\
\hline ВTP-2 & 226 & 156 & 156 & 156 & 156 & 156 & 44.87 & 0.00 & 0.00 & 0.00 & 0.00 \\
\hline ВTP-3 & 234 & 191 & 187 & 186 & 183 & 183 & 27.87 & 4.37 & 2.18 & 1.64 & 0.00 \\
\hline ВТР-4 & 4,285 & 2,455 & 2,310 & 2,365 & 2,170 & 2,170 & 97.46 & 13.13 & 6.45 & 8.99 & 0.00 \\
\hline ВTP-5 & 3,180 & 2,080 & 1,930 & 1,900 & 1,900 & 1,900 & 67.37 & 9.47 & 1.58 & 0.00 & 0.00 \\
\hline UTP-1 & 1,815 & 1,885 & 1,745 & 1,695 & 1,695 & 1,650 & 10.0 & 14.24 & 5.76 & 2.73 & 2.73 \\
\hline
\end{tabular}




\begin{tabular}{|c|c|c|c|c|c|c|c|c|c|c|c|}
\hline \multirow{2}{*}{ Ahamd et al...(2016) } & \multicolumn{6}{|l|}{ TCIFS } & \multirow{2}{*}{$\begin{array}{l}\% \text { increase } \\
\text { NWCM }\end{array}$} & \multirow{2}{*}{$\begin{array}{l}\text { from } \\
\text { LCM } \\
\end{array}$} & \multirow{2}{*}{$\begin{array}{l}\text { the } \\
\text { VAM }\end{array}$} & \multirow{2}{*}{$\begin{array}{l}\text { minimal } \\
\text { IAM }\end{array}$} & \multirow{2}{*}{$\begin{array}{l}\text { total cost } \\
\text { NEWA }\end{array}$} \\
\hline & NWCM & LCM & VAM & IAM & NEWA & OPTIMAL & & & & & \\
\hline UTP-3 & 14,725 & 14,625 & 13,225 & 13,075 & 12,475 & 12,475 & 18.04 & 17.23 & 6.01 & 4.80 & 0.00 \\
\hline UTP-4 & 13,100 & 9,800 & 9,200 & 9,200 & 9,200 & 9,200 & 42.39 & 6.52 & 0.00 & 0.00 & 0.00 \\
\hline UTP-5 & 8,150 & 6,450 & 6,000 & 5,850 & 5,600 & 5,600 & 45.53 & 15.18 & 7.14 & 4.46 & 0.00 \\
\hline
\end{tabular}

The comparative results obtained in Table 1 are also depicted using bar graphs and the results are given in Figure 1.

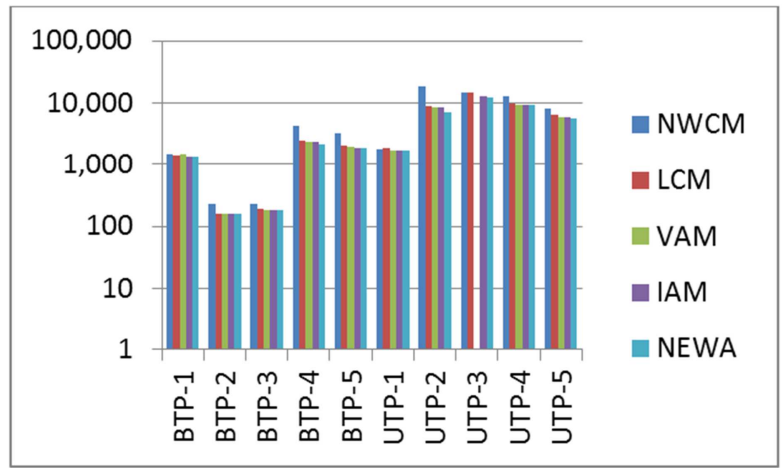

Figure 1. Comparative Stud of the Result obtained by NWCM, LCM, VAM, IAM and NEW method.

Line graphs for the percentage deviation (of the NWCM, LCM, VAM, IAM) with New method from minimal total cost solution) obtained in Table 1 are presented in Figure 2.

As seen from the above table, new method is more efficient than NWCM, LCM, VAM and IAM in every case where an improvement in efficiency was possible (09 / 10 case). Further, to all these problems, the percentage deviation in the total costs from the optimal cost in cases of NEWA method is the least.

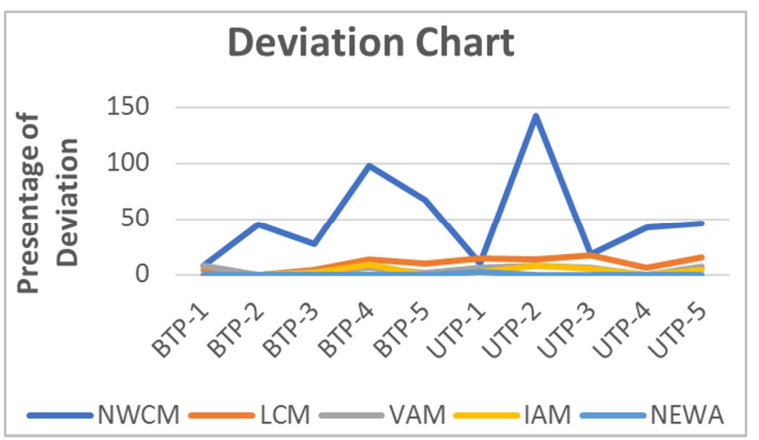

Figure 2. Percentage of Deviation of the Results obtained by NWCM, LCM, VAM, IAM and NEW method.

In addition this section provides performance comparisons among the developed various well-known methods NWCM, VAM, TDM, TDSM and New method through the solutions obtained from disparate problems. Comparative assessments are performed and illustrated in the immediately following sections. The detailed representation of the numerical data of Table 2. Is provided in Appendix 2.

Table 2. Comparative results of NWCM, VAM, TDM, TDSM and New method for 5 benchmark instances.

\begin{tabular}{|c|c|c|c|c|c|c|c|c|c|c|c|}
\hline \multirow{2}{*}{ Eghbal Hosseini [13] } & \multicolumn{3}{|c|}{$\operatorname{TCIFS}\left(I_{F S}\right)$} & \multirow[b]{2}{*}{ TDM } & \multirow[b]{2}{*}{ TDSM } & \multirow[b]{2}{*}{ OPTIMAL } & \multirow{2}{*}{$\begin{array}{l}\text { Percentage } \\
\text { NEWA }\end{array}$} & \multirow{2}{*}{$\begin{array}{l}\text { of } \\
\text { NWC }\end{array}$} & \multirow{2}{*}{$\begin{array}{l}\text { from } \\
\text { VAM }\end{array}$} & \multirow{2}{*}{$\begin{array}{l}\text { optimal } \\
\text { TDM }\end{array}$} & \multirow{2}{*}{$\begin{array}{l}\text { result } \\
\text { TDSM }\end{array}$} \\
\hline & NEWA & NWC & VAM & & & & & & & & \\
\hline Problem1. & 3,520 & 3,680 & 3,670 & 3,570 & 3,710 & 3520 & 0.00 & 4.54 & 4.26 & 1.42 & 5.40 \\
\hline Problem 2. & 610 & 670 & 650 & 630 & 610 & 610 & 0.00 & 9.83 & 6.55 & 3.28 & 0.00 \\
\hline Problem3. & 743 & 1,015 & 779 & 779 & 781 & 743 & 0.00 & 36.60 & 4.84 & 4.84 & 5.11 \\
\hline Problem4. & 490 & 1,451 & 490 & 490 & 490 & 490 & 0.00 & 196.1 & 0.00 & 0.00 & 0.00 \\
\hline Problem5. & 722 & 2,251 & 844 & 935 & 979 & 722 & 0,00 & 211.70 & 16.89 & 29.50 & 35.500 \\
\hline
\end{tabular}

The comparative results obtained in Table 2 are also depicted using bar graphs and the results are given in Figure 3.

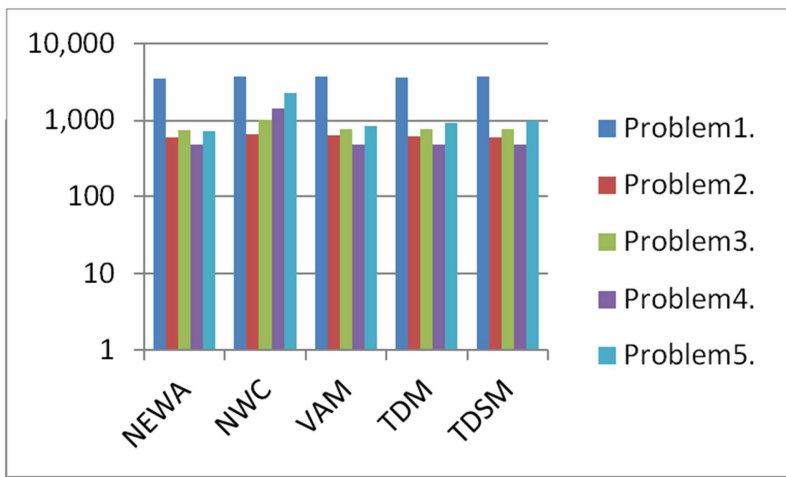

Figure 3. Comparative Study of the result obtained by NWCM, VAM, TDM, TDSM with New Method.

Line graphs for the percentage deviation (of the NWCM, VAM, TDM and TDSM, with New method from minimal total cost solution) obtained in Table 2 are presented in Figure 4.

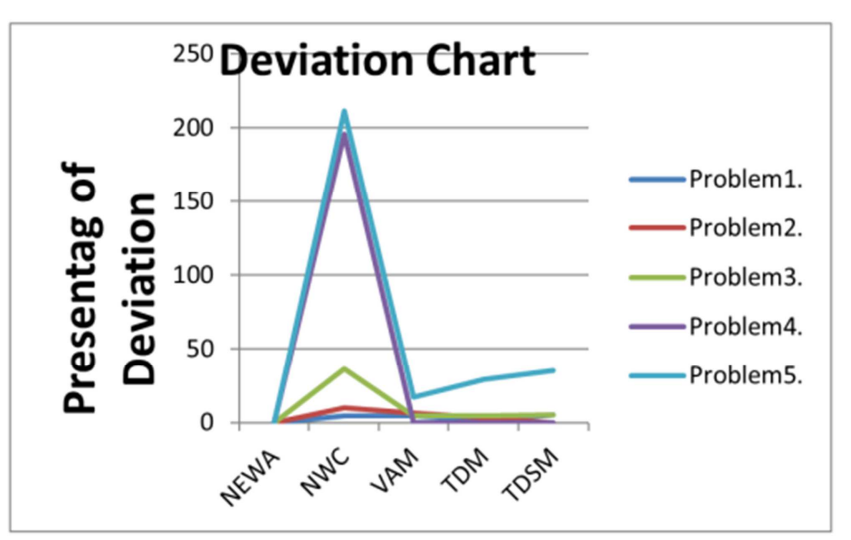

Figure 4. Percentage of Deviation of the Results obtained by NWCM, VAM, TDM, TDSM and NEW method.

It can clearly be seen from Table 2, and Figures $3 \& 4$ that the proposed method (NEWA) is more efficient than NWCM, VAM, TDM and TDSM in every case.

In addition, Performance measure of NEWA over NWCM, 
LCM, and VAM for 7 randomly generated numerical problems shown in the Table 3 is provided in Appendix 3.

Table 3. A comparative study of NWCM, LCM, VAM and NEWA for 7 randomly generated problem.

\begin{tabular}{|c|c|c|c|c|c|c|c|c|c|}
\hline & TCIFS & & & & Minimal T.cost & Percentage of & Deviation & from optimal & result \\
\hline & NWCM & LCM & VAM & NEWA & (by Lingo) & NWCM & LCM & VAM & NEWA \\
\hline Problem1. & 21.250 & 10,600 & 7,100 & 7,100 & 7,100 & 199.30 & 49.30 & $0 . .00$ & $0 . .00$ \\
\hline Problem2. & 4,452 & 2,878 & 2,025 & 2,004 & 2,004 & 122.20 & 43.61 & 1.05 & 0.00 \\
\hline Problem 3 & 12,650 & 4,350 & 4,350 & 4,350 & 4,350 & 190.80 & 0.00 & 0.00 & 0.00 \\
\hline Problem 4 & 1,630 & 1,240 & 1,160 & 1,090 & 1,090 & 49.54 & 13.76 & 6.42 & 0.00 \\
\hline Problem 5 & 1,722 & 811 & 363 & 363 & 363 & 374.38 & 123.41 & 0.00 & 0.00 \\
\hline Problem 6 & 754 & 653 & 640 & 640 & 640 & 17.81 & 2.03 & 0.00 & 0.00 \\
\hline
\end{tabular}

The comparative results obtained in Table 3 are also depicted using bar graphs and the results are given in Figure 5.

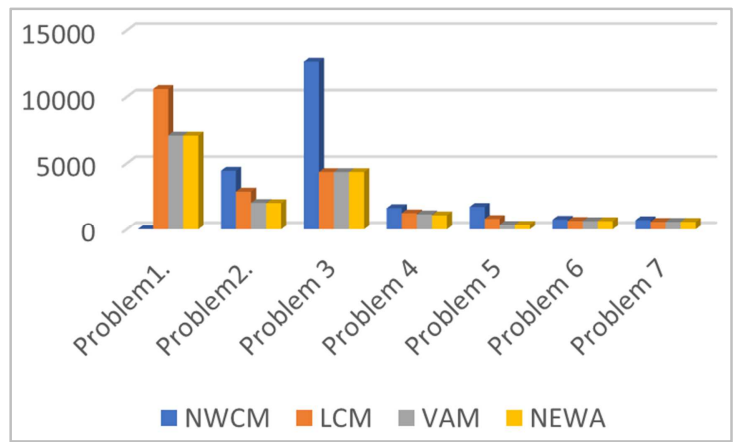

Figure 5. Comparative Study of the Result obtained by NWCM, LCM, VAM, with NEWA Method.

Line graphs for the percentage deviation (NWCM, LCM, VAM with NEWA Method) from minimal total cost solution obtained in Table 3 are presented in Figure 6.

It can easily be observed the above results (Table 3, Figure 5 and Figure 6), new method yields better results to all the problems in Table 3 compared with NWCM, LCM and VAM.

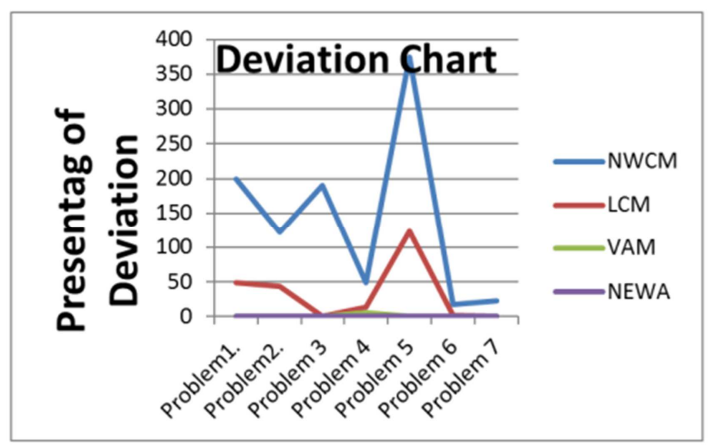

Figure 6. Percentage of Deviation of the Results obtained by NWCM, LCM, VAM and NEWA Method.

A comparative results obtained by ZSM, VAM, JHM and New method for the seven benchmark instances are shown in the following Table 4. Detailed data representation of these seven problems is provided in Appendix 4.

Table 4. A comparative results obtained by ZSM, VAM, JHM and NEWA method for the seven benchmark instances.

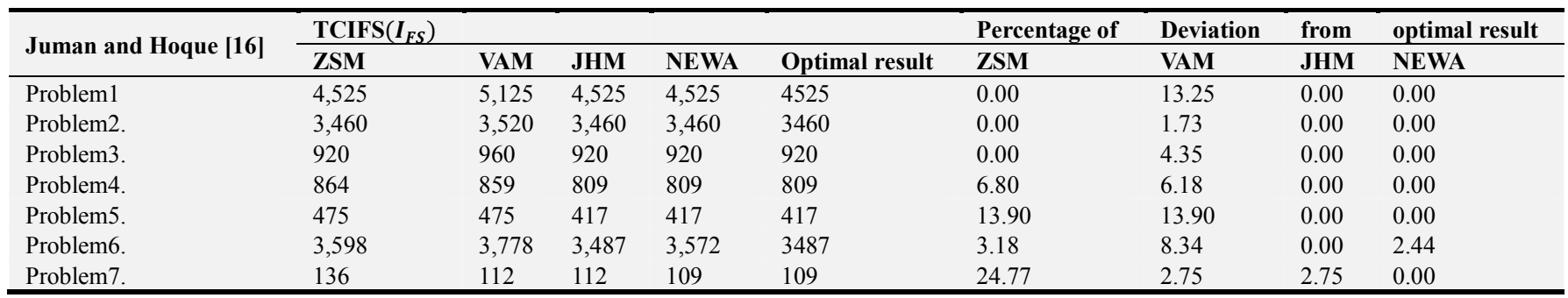

The comparative results obtained in Table 4 are also depicted using bar graphs and the results are given in Figure 7.

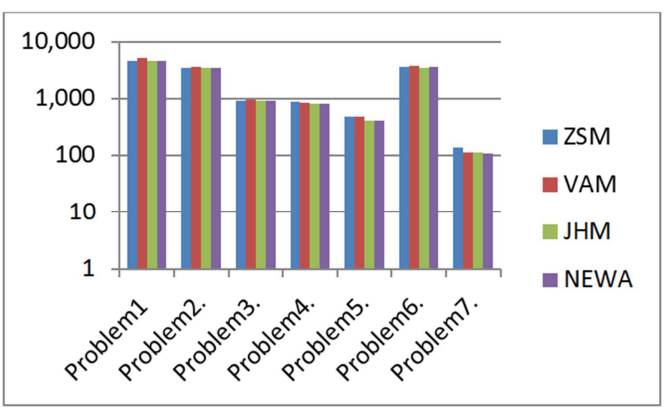

Figure 7. Comparative Study of the Result obtained by ZSM, VAM, JHM with NEW Method.
Line graphs for the percentage deviation (of the ZSM, VAM, JHM and New method) from minimal total cost solution obtained in Table 4 are depicted in Figure 8.

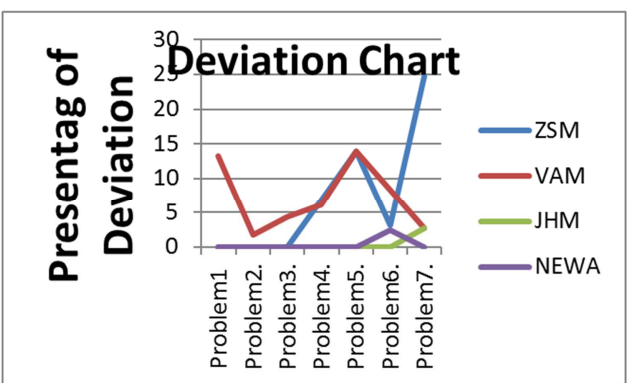

Figure 8. Percentage of Deviation of the Results obtained by ZSM, VAM, JHM and NEWA Method. 
Based on the above results (Table 4, Figures $7 \& 8$ ), new method better than ZSM and VAM. It provides the same results as JHM except one instances (Problem 6).

In addition to above benchmark instances, we have also studied some other numerical example problems chosen from
Ahmed et al.[3] in order to determine the performance of our new method over the available 14 approaches. The obtained results are presented in Table 5. Detailed data representation of these four example problems are provided in Appendix 5.

Table 5. Comparative results obtained by 14 available approaches and NEWA method for the four benchmark instances.

\begin{tabular}{|c|c|c|c|c|}
\hline \multirow{2}{*}{ Methods. } & Total initial & cost feasible & for solution & the \\
\hline & Ex.1 & Ex.2 & Ex.3 & Ex.4 \\
\hline North West Corner Method (NWCM) & 4400 & 4,160 & 540 & 1,500 \\
\hline Row Minimum Method (RMM) & 2,850 & 4,120 & 470 & 1,450 \\
\hline Column Minimum Method (CMM) & 3,600 & 3,320 & 435 & 1,500 \\
\hline Least Cost Method (LCM) & 2,900 & 3,500 & 435 & 1,450 \\
\hline Vogel's Approximation Method (VAM) & 2,850 & 3,320 & 470 & 1,500 \\
\hline Highest Cost Difference Method (HCDM) & 2,900 & 3,620 & 435 & 1,450 \\
\hline Average Cost Method (ACM) & 2,900 & 3,320 & 455 & 1,440 \\
\hline TOCM-MMM Approach & 2,900 & 3,620 & 435 & 1,450 \\
\hline TOCM-VAM Approach & 2,850 & 3,620 & 430 & 1,450 \\
\hline TOCM-EDM Approach & 2,850 & 3,620 & 435 & 1,450 \\
\hline TOCM-HCDM Approach & 2,900 & 3,620 & 435 & 1,450 \\
\hline ATM Approach ATM & 2,850 & 3,320 & 415 & 1,390 \\
\hline Proposed New Method & 2,850 & 3,320 & 410 & 1,390 \\
\hline Optimal Solution & 2,850 & 3,320 & 410 & 1,390 \\
\hline
\end{tabular}

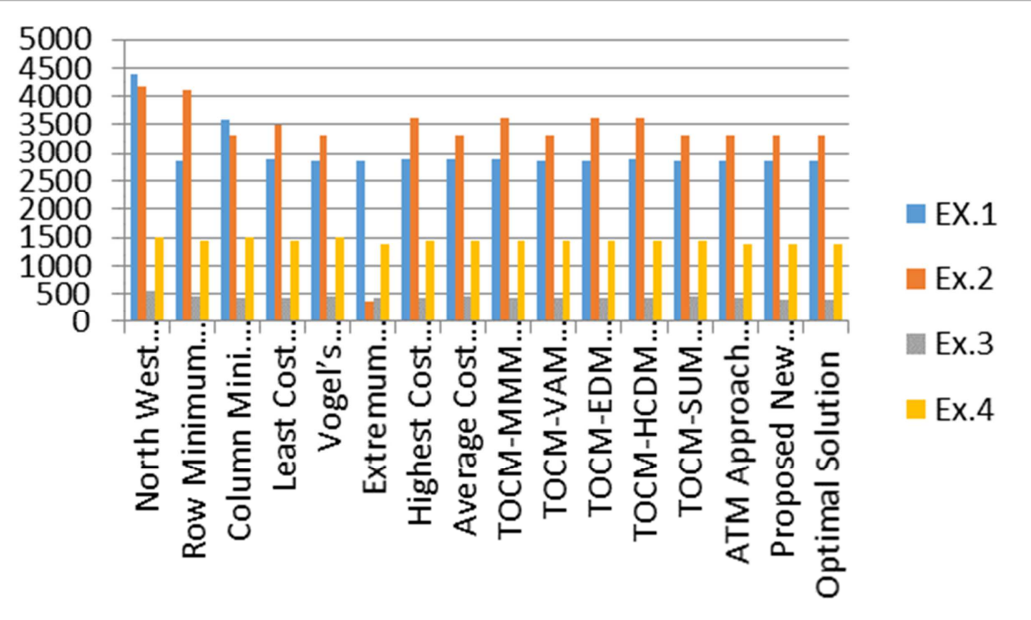

Figure 9. Comparative Study of the result obtained by our NEWA method against the existing 14 approaches.

Based on the above results (Table 5, Figure 9), new method better than other 14 approaches.

Next comparative results obtained by NWCM, LCM, VAM, and New method for the six benchmark instances are shown in the following Table 6. Detailed data representation of these six problems is provided in Appendix 6.

Table 6. Performance measure of new method (NM) over NWCM, LCM and VAM.

\begin{tabular}{|c|c|c|c|c|c|c|c|c|c|}
\hline \multirow{2}{*}{ Wali Ullah1 et al., [25] } & \multicolumn{5}{|c|}{$\operatorname{TCIFS}\left(I_{F S}\right)$} & \multirow{2}{*}{$\begin{array}{l}\text { Percentage optimal } \\
\text { NWCM }\end{array}$} & \multirow{2}{*}{$\begin{array}{l}\text { Of result } \\
\mathrm{LCM}\end{array}$} & \multirow{2}{*}{$\begin{array}{l}\text { Deviation } \\
\text { VAM } \\
\end{array}$} & \multirow{2}{*}{$\begin{array}{l}\text { from } \\
\text { NEWA } \\
\end{array}$} \\
\hline & NWCM & LCM & VAM & NEWA & OPTIMAL & & & & \\
\hline Problem1. & 2,820 & 2,090 & 2,070 & 2,040 & 2,040 & 38.23 & 2.45 & 1.47 & 0.00 \\
\hline Problem2. & 914 & 674 & 750 & 674 & 674 & 35.61 & 0.00 & 11.27 & 0.00 \\
\hline Problem3. & 25,530 & 21,450 & 21,030 & 20,550 & 20,550 & 24.33 & 4.38 & 2.33 & 0.00 \\
\hline Problem4. & 1,010 & 988 & 988 & 968 & 968 & 4.34 & 2.07 & 2.07 & 0.00 \\
\hline Problem5. & 621 & 423 & 391 & 381 & 381 & 63.00 & 11.02 & 2.62 & 0.00 \\
\hline Problem 6 & 92,450 & 63,550 & 66,300 & 63,300 & 63,300 & 46.05 & 0.39 & 4.74 & 0.00 \\
\hline
\end{tabular}

The comparative results obtained in Table 6 are also depicted using bar graphs and the results are given in Figure 10 . 


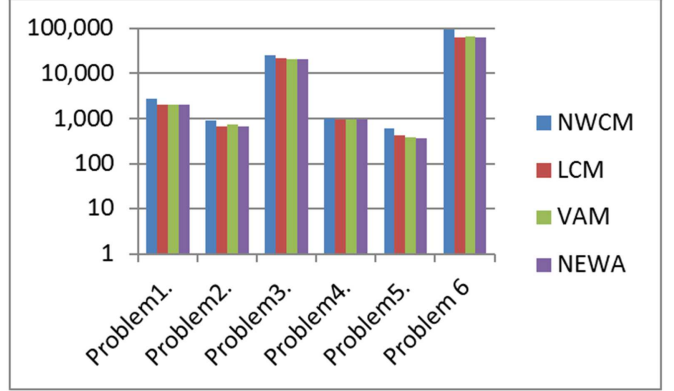

Figure 10. Comparative Study of the result obtained by our new method against the existing NWCM, LCM and VAM.

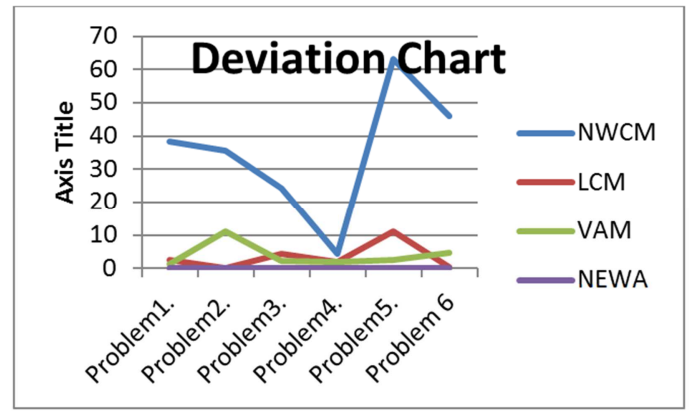

Figure 11. Percentage of Deviation of the Results obtained by NWCM, LCM, VAM and NEWA Method.

Note that, although, our method yields the optimal solution to all benchmark instances above, the available four approaches (NWCM, LCM and VAM).

\section{Conclusion}

In this study, a new approach for attaining a near-optimal solution to the TP was proposed. Different techniques have been developed in the literature for solving the transportation problem. In specific methodologies concentrated on finding an initial basic feasible solution and the other to find the optimal solution. It has proven to provide an optimal solution to a certain degree of satisfaction within a reasonable computational time even for large scale TPs.

However, This new method is based on the allocation of transportation costs in the transportation matrix and can be applied to all balance and unbalance transportation problems, using more variables. Also, the algorithm is easy to understand and gives us the optimal solutions in finite number of iterations

Using this coding we solved 35 problems where 28 of them are chosen from the literature and 7 of them are randomly generated. A comparative study shows that NEWA led to the minimal total cost solutions to 33 out of 35 considered problems. Hence, the comparative assessments of the above different cases show that both the modified NEW algorithm and JHM are efficient as compared to the studied approaches of this paper in terms of quality of the solution.

\section{Acknowledgements}

This work was partially supported by the International grant of Rajarata University of Sri Lanka.

\section{Appendix}

\section{Appendix 1. Numerical Examples, Based on [4]}

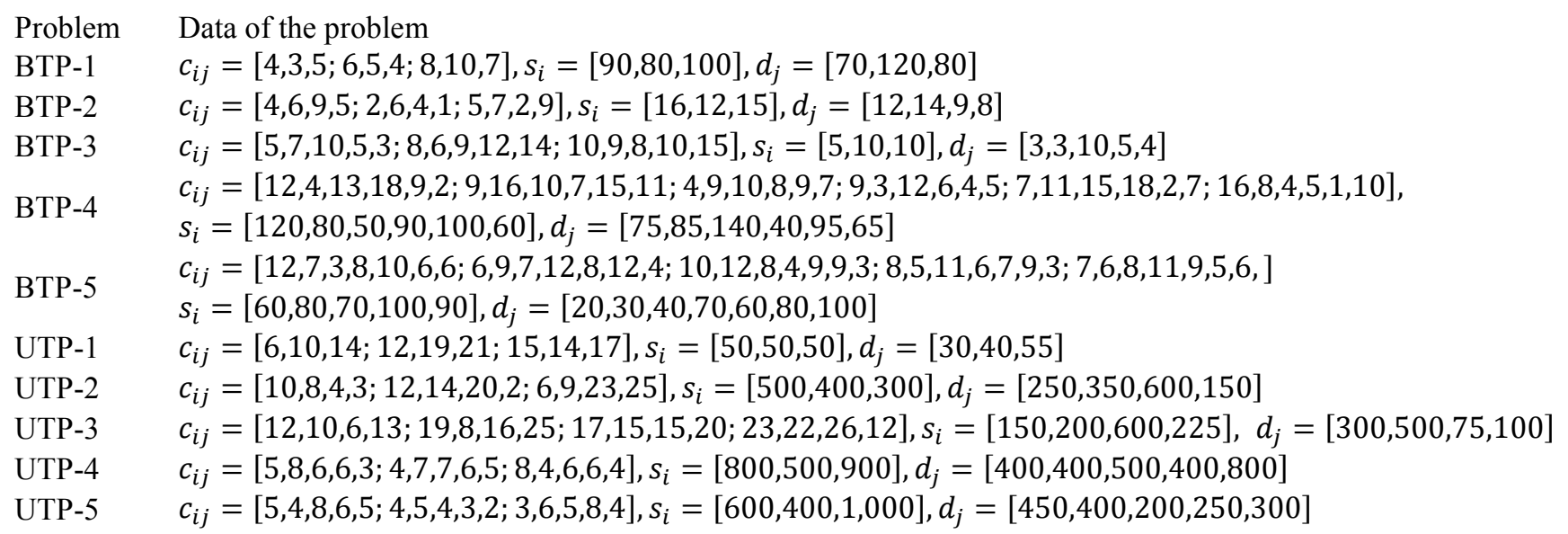

\section{Appendix 2. Numerical Examples, Based on [13]}

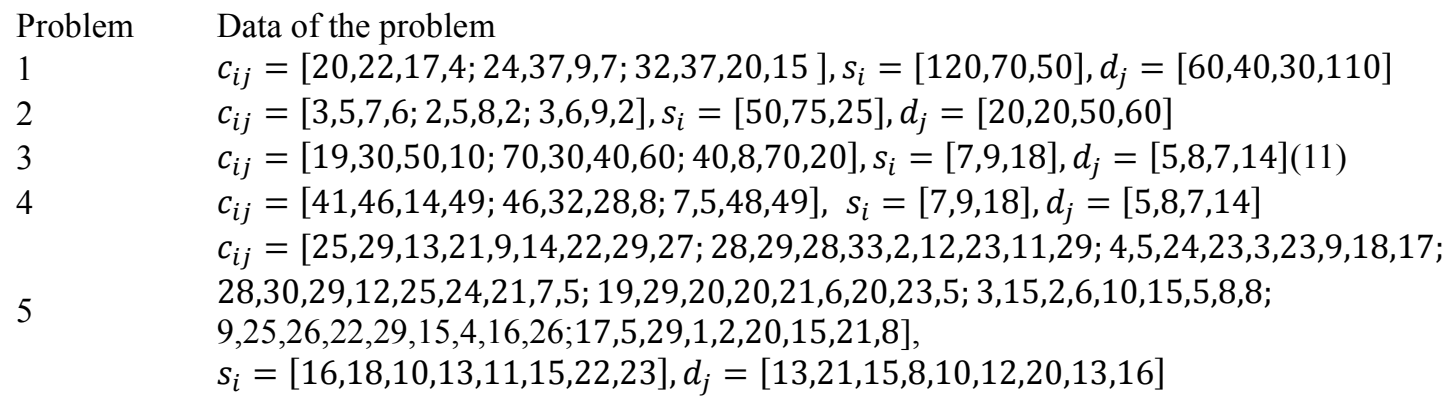




\section{Appendix 3. Randomly Generated Numerical Problems}

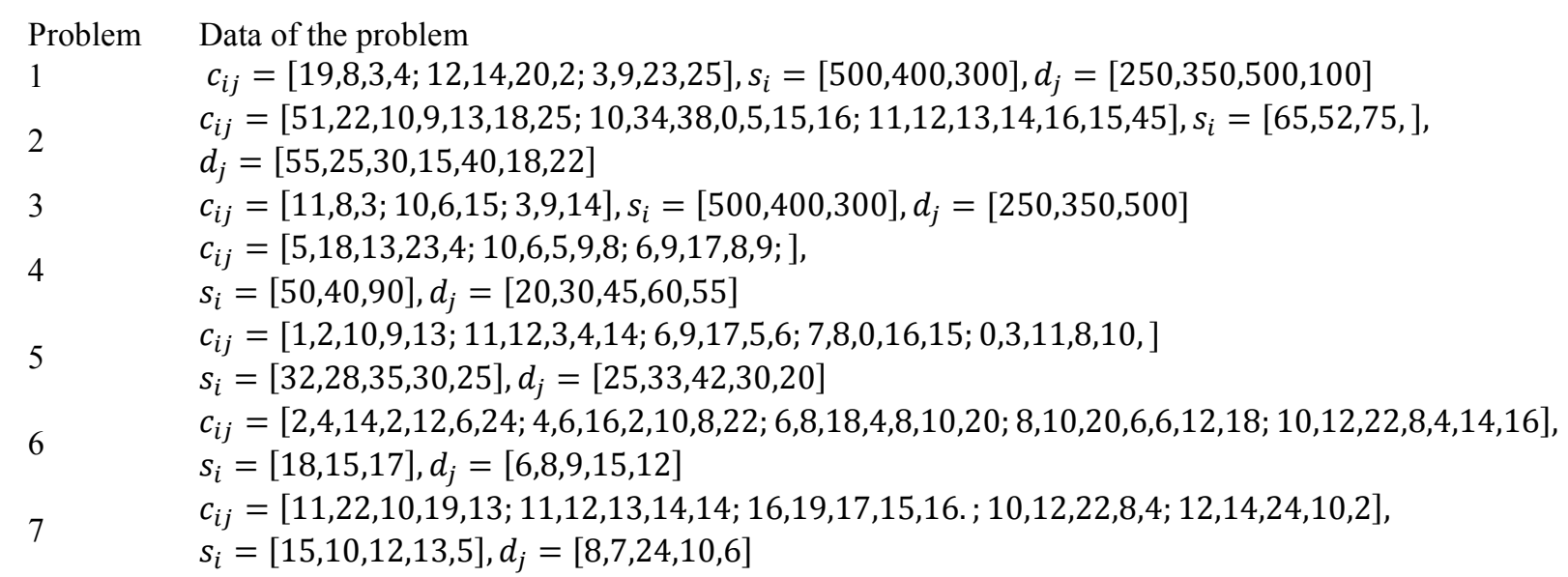

\section{Appendix 4. Numerical Examples, Based on [16]}

Problem Data of the problem

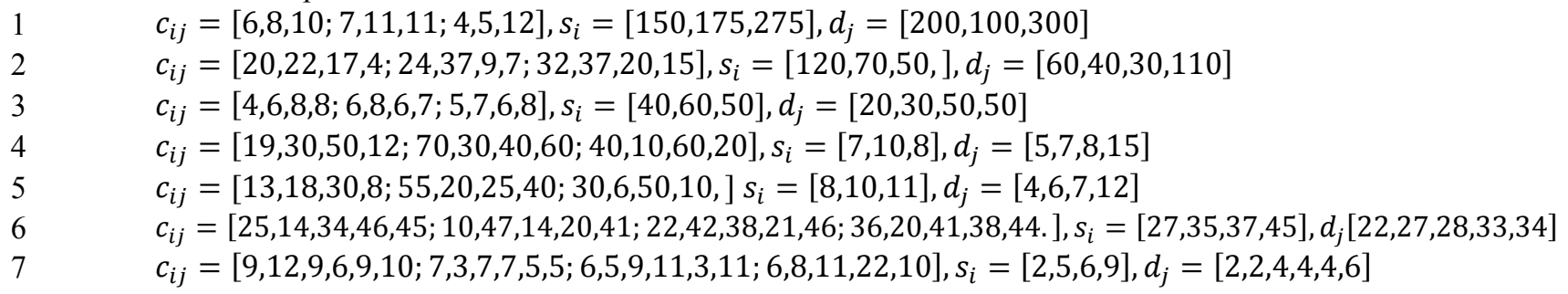

\section{Appendix 5. Numerical Examples, Based on [3]}

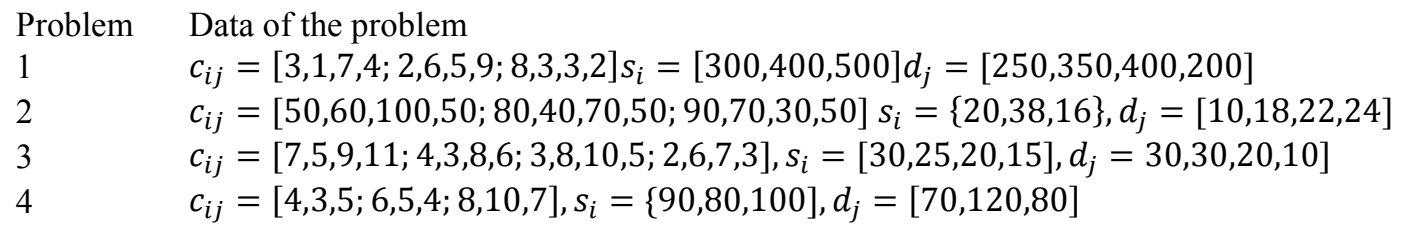

\section{Appendix 6. Numerical Examples, Based on [25]}

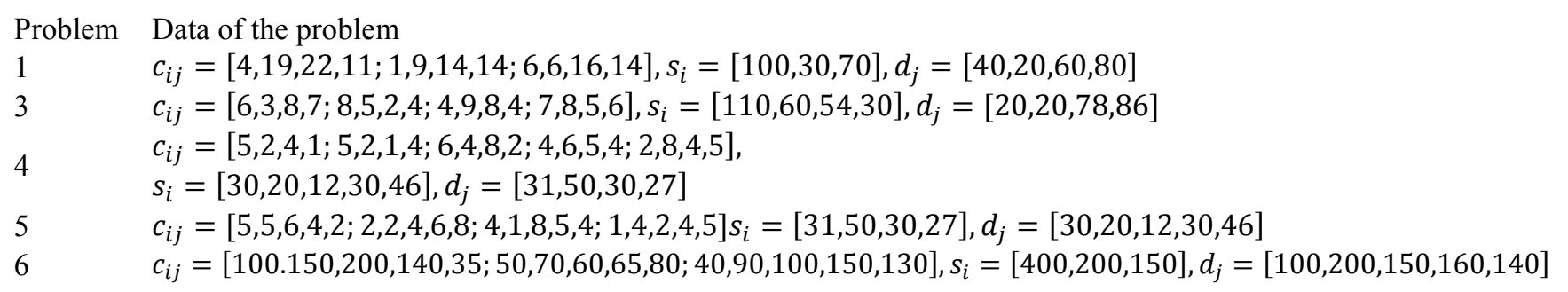

\section{References}

[1] P. Adhikari and G. B. Thapa, "A Note on Feasibility and Optimality of Transportation Problem", Journal of the Institute of Engineering, 10 (1), 2000, pp. 59-68.

[2] S. Akpana, T. Ugbeb, J. Usenc and O. Ajahd. "A Modified Vogel Approximation Method for Solving Balanced Transportation Problems", American Scientific Research Journal for Engineering, Technology, and Sciences (ASRJETS), 14 (3), 2015, pp. 289-302.

[3] M. M. Ahmed, A. R. Khan, S. Uddin and F. Ahme "A New Approach to Solve Transportation Problems", Open Journal of
Optimization, 5, 2016, pp. 22-30.

[4] M. M. Ahmed, A. R. Khan, F. Ahmed, Md. S. Uddin, "Incessant Allocation Method for Solving Transportation Problems", American Journal of Operations Research, 6, 2016, pp. 236-244.

[5] A. Charnes, W. W Cooper and A. Henderson, "An Introduction to Linear Programming” John Wiley \& Sons, New York. 1953.

[6] G. B. Dantzig, "Linear programming and extensions". Princeton, NJ: Princeton University press", 1963.

[7] N. M. Deshmukh, "An Innovative Method For Solving Transportation Problem", International Journal of Physics and Mathematical Sciences, Vol. 2 (3), 2012, pp. 86-91. 
[8] E. M. U. S. B., Ekanayake, S. P. C., Perera, W. B. Daundasekara, and Z. A. M. S. Juman, "A Modified Ant Colony Optimization Algorithm for Solving a Transportation Problem" Journal of Advances in Mathematics and Computer Science, 2020, 35 (5), 83-101.

[9] L. R. Ford, and D. R. Fulkerson, "Solving the transportation Problem”, The RAND Corporation. 1956.

[10] S. K. Goyal, "Improving VAM for unbalanced transportation problems", Journal of Operational Research Society 35,1984, pp. 1113-1114.

[11] A. T. Hamdy, "Operations Research: An Introduction. 8th Edition, Pearson Prentice Hall, Upper Saddle River. 2007.

[12] F. L. Hitchcock, "The distribution of a product from several resources to numerous localities", J. Math. Phy., 20,1941, pp. 224-230.

[13] E. Hosseini, "Three New Methods to Find Initial Basic Feasible Solution of Transportation Problems", Applied Mathematical Sciences, 11 (37), 2017, pp. 1803-1814.

[14] T. Imam, G. Elsharawy, M. Gomah M, I. Samy, "Solving Transportation Problem", Using Object-Oriented Model. Int. J. comput. Sci. Netw. Secur. 9 (2), 2009, pp. 353-361.

[15] Z. A. M. S. Juman, M. A. Hoque, "An efficient heuristic approach for solving the transportation problem", Proceedings of the 2014 International Conference on Industrial Engineering and Operations Management Bali, Indonesia, 2014.

[16] Z. A. M. S. Juman, M. A. Hoque, "An efficient heuristic to obtain a better initial feasible solution to the transportation problem”, Applied Soft Computing 34, 2015, pp. 813-826.
[17] Z, A, M, S. Juman, N. G. S. A. Nawarathne, "An efficient alternative approach to solve a transportation problem. Ceylon Journal of Science 48 (1), 2019, pp. 19-29.

[18] T. C. Koopmans, "Optimum Utiliztion of Transportation System”, Econometrica, Supplement vol 17, 1949.

[19] S. Korukoglu, S. Bali, "A improve Vogel Approximation Method for the transformation Problem", Mathematical and computational Applications 16 (2), 2011, pp. 370-381.

[20] S. S. Kulkarni, H. G. Datar, "On Solution To Modified Unbalanced Transportation Problem". Bulletion of the Marathwada Mathematical Society 11 (2), 2010, pp. 20-26.

[21] V. Manisha, M. V. Sarode, "Application of a Dual Simplex method to Transportation Problem to minimize the cost", International Journal of Innovations in Engineering and Science, 2 (7), 2017.

[22] G. Monge. Mémoire sur la théorie des déblais et des remblais. Histoire de l'Académie Royale des Sciences de Paris, avec les Mémoires de Mathématique et de Physique pour la même année, pages 666-704, 1781.

[23] N. V. Reinfeld and W. R. Vogel, 1958. Mathematical Programming. Englewood Cliffs, NJ: Prentice-Hall.

[24] A. S. Soomro, M. Junaid and G. A. Tularam "Modified Vogel's Approximation Method For Solving Transportation Problems", Mathematical Theory and Modeling, 5 (4), 2015.

[25] M. W. Ullah, M. A. Uddin and R. A. Kawser, "Modified Vogel's Approximation Method for Obtaining a Good Primal Solution of Transportation Problems", Annals of Pure and Applied Mathematics, 11 (1), 2016, pp. 63-71. Thanks lot. 